\title{
The KCNE genes in hypertrophic cardiomyopathy: a candidate gene study
}

\author{
Paula L Hedley ${ }^{1,2}$, Ole Haundrup ${ }^{3}$, Paal S Andersen ${ }^{4}$, Frederik H Aidt ${ }^{1}$, Morten Jensen ${ }^{5}$, \\ Johanna C Moolman-Smook ${ }^{2}$, Henning Bundgaard ${ }^{5}$ and Michael Christiansen ${ }^{1 *}$
}

\begin{abstract}
Background: The gene family KCNE1-5, which encode modulating $\beta$-subunits of several repolarising $\mathrm{K}^{+}$-ion channels, has been associated with genetic cardiac diseases such as long QT syndrome, atrial fibrillation and Brugada syndrome. The minK peptide, encoded by KCNE1, is attached to the Z-disc of the sarcomere as well as the T-tubules of the sarcolemma. It has been suggested that minK forms part of an "electro-mechanical feed-back" which links cardiomyocyte stretching to changes in ion channel function. We examined whether mutations in KCNE genes were associated with hypertrophic cardiomyopathy $(\mathrm{HCM})$, a genetic disease associated with an improper hypertrophic response.

Results: The coding regions of KCNE1, KCNE2, KCNE3, KCNE4, and KCNE5 were examined, by direct DNA sequencing, in a cohort of 93 unrelated HCM probands and 188 blood donor controls.

Fifteen genetic variants, four previously unknown, were identified in the HCM probands. Eight variants were nonsynonymous and one was located in the $3^{\prime} U T R$-region of KCNE4. No disease-causing mutations were found and no significant difference in the frequency of genetic variants was found between HCM probands and controls. Two variants of likely functional significance were found in controls only.

Conclusions: Mutations in KCNE genes are not a common cause of HCM and polymorphisms in these genes do not seem to be associated with a propensity to develop arrhythmia
\end{abstract}

\section{Background}

Hypertrophic cardiomyopathy (HCM) is a condition characterised by increased wall (predominantly septal) thickness, diastolic dysfunction, and an increased risk of heart failure, stroke and cardiac arrhythmia [1]. The disease has a prevalence of 1:500 in young adults [2], and is considered a hereditary disease caused by mutations in more than 12 genes [3], most of which encode proteins of the sarcomere. The disease exhibits considerable intra-allelic as well as phenotypic heterogeneity. Presently, a genetic aetiology can be identified in $70 \%$ of familial cases and 30\% of non-familial cases [3].

Recently, mutations in genes coding for ion channels have been shown to cause cardiomyopathy. Mutations in $S C N 5 A$, coding for the $\alpha$-subunit of the ion channel conducting the depolarising $I_{\mathrm{Na}}$-current $[4,5]$, and in

\footnotetext{
*Correspondence: mic@ssi.dk

'Department of Clinical Biochemistry and Immunology, Statens Serum Institut, Copenhagen, Denmark

Full list of author information is available at the end of the article
}

$A B C C 9$ [6], coding for the cardiac specific SUR2A subunit of the $\mathrm{K}_{\mathrm{ATP}}$ potassium channel, have been associated with dilated cardiomyopathy (DCM). The DCM caused by mutations in both $S C N 5 A$ and $A B C C 9$ is accompanied by cardiac arrhythmia.

The KCNE-gene family (KCNE1-5) encodes five small single transmembrane peptides (minK and MiRP1-4, respectively) that function as $\beta$-subunits to potassium and pacemaker ion channels $[7,8]$. The KCNE peptides confer distinctive characteristics to a variety of currents [9-11]. For example, the slow increase and high conductance characteristic of $\mathrm{I}_{K s}$ is conferred by $\operatorname{minK}$ (encoded by KCNE1) to the $\alpha$-subunit (encoded by KCNQ1) [12]. The KCNE peptides are also involved in correct trafficking of $\alpha$-subunits [13]. Mutations in $K C N E$ genes have been associated with a number of diseases, i.e. cardiac arrhythmia by mutations in KCNE1 (long QT syndrome and Jervell Lange Nielsen Syndrome) [14-17], KCNE2 (long QT syndrome, atrial fibrillation, drug induced ventricular fibrillation) [18-20], KCNE3 (Brugada syndrome)

\section{Biomed Central}


[21] and KCNE5 (atrial fibrillation) [22]; mutations in $K C N E 3$ have also been associated with periodic paralysis and hypo-and hyperkalemic disorders [23]. Furthermore, kcne2 null mice develop rhythm disturbances [24] and kcne 2 null pups to kcne 2 null dams develop hypertrophy among other abnormalities as a consequence of hypothyroidism [25]. This suggests that in addition to the development of arrhythmias, mutations in KCNE2 could give rise to cardiac hypertrophy through the dysregulation of thyroid hormones. Likewise, other investigations using kcne 2 null mice have revealed an association with gastric pathology [26]. These finding suggest that the KCNE genes may influence phenotypic presentation of HCM in multiple ways.

All $K C N E$ genes are expressed in the heart but to a varying extent [27]. The minK and MirP peptides exhibit considerable functional promiscuity, consequently, they may substitute for each other with different $\alpha$-subunits [28] and the relative levels of peptides in different parts of the heart influence the regional variation of ion channel function [27].

Yeast-two-hybrid $(\mathrm{Y} 2 \mathrm{H})$ experiments have shown that minK is linked to the $\mathrm{z}$-disc of the sarcomere via interaction with titin-cap (telethonin) [29]. The link between the T-tubule, where minK is attached and the Z-disc, has been suggested to constitute a "mechano-electrical feed-back system", linking the function of repolarising ion channels to stretch of the cardiomyocytes [29].

The Z-disc proteins are involved in the control of cardiac hypertrophy as mutations in the protein constituents of the Z-disc, T-cap, titin, muscle LIM protein, actinin and cypher/ZASP, have been shown to cause both HCM and DCM [30,31]. The electrical remodelling seen in heart failure is characterised by a marked increase in the expression of KCNE1 [32] in the heart.

We hypothesised that variants in KCNE genes, might result in changes in mechano-electrical feed-back, and could be responsible for a maladaptation of the stretchresponse of the heart. This could explain an exaggerated hypertrophic response and thus HCM development in patients with mutations in Z-disc proteins. Alternatively, an increased occurrence of electrophysiologically significant $K C N E$ variants might explain the increased propensity of arrhythmia in HCM.

We screened the genes KCNE1, KCNE2, KCNE3, $K C N E 4$, and $K C N E 5$ for genetic variants in 93 unrelated probands with HCM and related the findings to occurrence of disease or propensity to a particular phenotype.

\section{Results}

No putative disease causing mutations were found in $\mathrm{HCM}$ index patients in any of the five $K C N E$ genes. Fifteen genetic variants were identified; four of which were previously unknown. Fourteen of the genetic variants were located in the coding regions of the genes. The variants are detailed in Table 1 . All variants were in Hardy-Weinberg equilibrium, when the variants were so frequent that this could be assessed.

Two variants, p.M1T in KCNE3 and p.E141A in $K C N E 4$, were found in single controls. The p.M1T variant abolishes the translation initiation codon and most likely results in haplo-insufficiency. The p.E141A variant, affects an amino acid which is conserved in seven species, and represents a charge change and may well modify the functional properties.

Some of the identified variants have previously been associated with arrhythmia, i.e. p.S38G in KCNE1 and p. P33S in KCNE5, that are known polymorphisms associated with increased risk of atrial fibrillation. There was no significant difference in the frequency of any of the polymorphisms between HCM and the normal population. Two variants, i.e. p.D85N in KCNE1 and p.T8A in $K C N E 2$ have previously been associated with increased risk for drug-induced ventricular fibrillation. For both variants, the frequency was lower in HCM, for p.D85N rare allele frequency $0.5 \%$ vs $1.2 \%$ in controls, and for $\mathrm{p}$. T8A a rare allele frequency of $0.5 \%$ vs. $4.3 \%$ in controls. For both variants the allele frequency was so low, however, that the difference is not significant when compensating for multiple comparisons.

The p.R83H variant in KCNE3 has previously been associated with hypo- and hyper-kalemia and paralysis [7], and here it was found in two cases. In one family the mutation was co-inherited with a mutation in troponin $\mathrm{T}$ and in another the comprehensive sarcomeric gene screening had not revealed other mutations. There were no special clinical characteristics of the carriers of the $\mathrm{p}$. $\mathrm{R} 83 \mathrm{H}$ variant. However, the p.R83H has, following the association with hypo- and hyper-kalemic paralysis, been described as a polymorphism in several populations [33].

None of the identified variants had any significant effect on splicing, i.e. did not interfere in silico with ESEs or SSEs.

\section{Discussion}

The $K C N E$ genes do not, despite the association with electromechanical feedback, seem to cause HCM, even though the number of probands examined does not preclude an involvement at the level of less than $1 \%$. However, except in special cases, there does not seem to be any reason for including $K C N E$ gene screening in the screening of genes in the genetic work-up of HCM.

The frequency of arrhythmia associated genetic variants was so low that it did not convincingly differ from that of controls and it cannot explain the increased occurrence of arrhythmia in HCM [34]. However, the previously arrhythmia-associated variants p.D85N $[18,35,36]$ and p.T8A [7] both occurred more frequently 
Table 1 Genetic variants within the KCNE genes identified in a Danish HCM cohort

\begin{tabular}{|c|c|c|c|c|c|c|}
\hline nucleotide & peptide & rs\# & Pop rare allele frequency & HCM rare allele frequency & Disease association & Reference \\
\hline \multicolumn{7}{|c|}{ KCNE1: [NM_000219.2/NP_000210.2] } \\
\hline c. $24 \mathrm{G}>\mathrm{A}$ & p.A8A & & 0.000 & 0.005 & & \\
\hline c.112G > A & p.G38S & rs17846179 & 0.494 & 0.376 & $\mathrm{AF}$ & [40] \\
\hline c.253G > A & p.D85N & rs1805128 & 0.012 & 0.005 & IVF, drug induced & {$[18,35,36]$} \\
\hline \multicolumn{7}{|c|}{ KCNE2: [NM_172201.1/NP_751951.1] } \\
\hline c. $22 \mathrm{~A}>\mathrm{G}$ & p.T8A & rs2234916 & 0.043 & 0.005 & IVF, drug-induced & \\
\hline \multicolumn{7}{|c|}{ KCNE3: [NM_005472.4/NP_005463.1] } \\
\hline C.2T > C & p.M1T & & 0.003 & 0.000 & & \\
\hline c.198T > C & p.F66F & rs2270676 & 0.104 & 0.080 & & \\
\hline c.248G > A & p.R83H & rs17215437 & 0.003 & 0.011 & Hypokalemia & {$[7,41]$} \\
\hline \multicolumn{7}{|c|}{ KCNE4: [NM_080671.2/NP_542402.2] } \\
\hline c. $69 \mathrm{C}>\mathrm{T}$ & p.S23S & rs12720447 & 0.011 & 0.006 & & \\
\hline $\mathrm{c} .81 \mathrm{C}>\mathrm{T}$ & p.G27G & rs3795886 & 0.730 & 0.717 & & \\
\hline c. $264 \mathrm{~T}>\mathrm{C}$ & p.P88P & rs10201907 & 0.949 & 0.933 & & \\
\hline c. $422 \mathrm{~A}>\mathrm{C}$ & p.E141A & & 0.003 & 0.000 & & \\
\hline c. $435 \mathrm{~T}>\mathrm{G}$ & p.D145E & rs12621643 & 0.712 & 0.724 & & \\
\hline c.471G > A & p.E157E & & 0.042 & 0.023 & & \\
\hline c. $* 19 G>C$ & $3^{\prime} U T R$ & rs10189762 & 0.059 & 0.046 & & \\
\hline \multicolumn{7}{|c|}{ KCNE5: [NM_012282.2/NP_036414.1] } \\
\hline c. $97 \mathrm{C}>\mathrm{T}$ & p.P33S & rs17003955 & $0.206^{*}$ & $0.150^{*}$ & $\mathrm{AF}$ & {$[22,42]$} \\
\hline
\end{tabular}

in controls than in HCM patients. We cannot exclude, however, that a small minority of HCM patients with arrhythmia associated variants in $K C N E$ genes have an increased propensity for arrhythmia.

The finding of very rare genetic variants with likely functional significance, i.e. p.M1T in KCNE3 and p. E141A in KCNE4, in controls is interesting and suggests that such variants may contribute to the arrhythmia risk in various conditions in the general population.

\section{Conclusions}

Our findings suggest that neither KCNE1, despite its physical association with the Z-disc [29], nor the other $K C N E$ genes are common causes of HCM.

\section{Methods}

\section{Patients}

Ninety-three unrelated consecutively diagnosed HCM patients identified at, or referred to, Copenhagen University Hospital, Rigshospitalet, Copenhagen, Denmark were included in the study. All patients were of Northern European descent. Patients were subjected to a full clinical evaluation including family history, physical examination, echocardiography and ECG. All fulfilled classical diagnostic criteria for HCM $[37,38]$. The mean age of index patients was 49 years, $62 \%$ were male, and $48 \%$ were familial. Ninety-two \% had septal hypertrophy, $6 \%$ apical hypertrophy and 2\% mid-ventricular hypertrophy. All patients had been screened for mutations in the coding regions of $M Y H 7, M Y B P C 3, T T N T 2$, TPM1, TNNI3, MYL3, MYL2, ACTC, TCAP, CSRP3, and exons 3,7,14,18, and 49 of $T T N$, as detailed in a previous study [3]. All index patients were also screened for mutations in GLA. In 32 index patients this screening had identified presumably disease-causing mutations, i.e. 12 in $M Y H 7,8$ in MYBPC3, 2 in each of TNNT2, TNNI3 and GLA, 1 in each of ACTC, TPM1, MYL3 and MYL2. Two patients were carriers of mutations in both $M Y L 2$ and $M Y H 7$. A control panel of 188 (50\% men) anonymous blood donors obtained from Rigshospitalet, Copenhagen, were used.

\section{Molecular genetic studies}

Genomic DNA was isolated from whole blood samples (Qiagen, Hilden, Germany). The genomic sequences of KCNE1, KCNE2, KCNE3, KCNE4, and KCNE5 were used for designing intronic primers covering the coding region of the genes. Primers and conditions are given in Table 2. DNA sequencing was performed using Big Dye technology. Variant numbering was verified using the Mutalyzer program [39].

\section{Disease-causation and association}

Genetic variants were considered disease-causing if 1) the nucleotide variation was deduced to result in a 
Table 2 Primer sequences, amplicon size and melting temperatures for the KCNE gene mutation screening

\begin{tabular}{|c|c|c|c|}
\hline Name & Sequence & $\begin{array}{c}\text { amplicon size } \\
\text { (bp) }\end{array}$ & $\operatorname{Tm}\left({ }^{\circ} \mathrm{C}\right)$ \\
\hline KCNE1.1F & 5' GCA GCA GTG GAA CCT TAA TG 3' & 225 & 58 \\
\hline KCNE1.1R & 5' CGG ATG TAG CTC AGC ATG AT 3' & & \\
\hline KCNE1.2F & 5' CTT CGG CTT CTT CAC CCT G 3' & 250 & 58 \\
\hline KCNE1.2R & 5' TTA GCC AGT GGT GGG GTT C 3' & & \\
\hline KCNE2.1F & 5' TCC GTT TTC CTA ACC TTG TTC 3' & 250 & 58 \\
\hline KCNE2.1R & 5' GCC ACG ATG ATG AAA GAG AAC 3' & & \\
\hline KCNE2.2F & 5' GAT GCT GAG AAC TTC TAC TAT G 3' & 300 & 58 \\
\hline KCNE2.2R & 5' GTC TGG ACG TCA GAT GTT AG 3' & & \\
\hline KCNE3F & 5' GCT AAG ATT TTA CCT GGG ATC TGA 3' & 626 & 65 \\
\hline KCNE3R & 5' TAT GCA CAA GGC TTC GGT CTA C 3' & & \\
\hline KCNE4F & 5' CTC TTG TCA GCT GTT TGG CGA ACC 3' & 886 & 65 \\
\hline KCNE4R & 5' CAC AGG CAC CTC CCG GAC TC 3' & & \\
\hline KCNE5F & 5' CCG CCG TGT CAC TCC CCG AAA 3' & 493 & 62 \\
\hline KCNE5R & 5' AGA TGA GGA GGG CGC GAA CCA 3' & & \\
\hline
\end{tabular}

missense mutation, frameshift and/or abnormal splicing; 2) if relevant, the variation affected a conserved amino acid; 3) the variation co-segregated with the disease in affected family members and; 4) if the variation was not identified among 188 ethnically controlled samples. In the absence of available family members for co-segregation studies, disease association was presumed if criteria 1, 2 and 4 were fulfilled. If the mutation had previously, in accordance with the criteria mentioned here and/or relevant functional studies, been associated with disease, disease causation was presumed when just the criteria 1 and 4 were met. The association between gene variants and disease was assessed by comparing the distribution of variants in disease group and controls. $\chi^{2}$-testing was used to examine for significant association using a level of significance of 0.05 , with correction for multiple comparisons, if such were made.

\section{Bioinformatics}

ESE/SSE-in silico assessment was performed using the online web-servers: FAS-ESS [34], RESCUE-ESE [35], HMMgene [36], GENSCANW [37] and ESEFinder v.3.0 [38]. Multiple species alignments were performed using ClustalW2 [39].

\section{Ethics}

Informed consent was obtained from study participants. The study was approved by the Local Science Ethics Committees, Copenhagen and Frederiksberg, protocol no. KF V92213.

\section{List of abbreviations}

DCM: dilated cardiomyopathy; HCM: hypertrophic cardiomyopathy; $\mathrm{Y} 2 \mathrm{H}$ : yeast-two-hybrid.

\section{Acknowledgements}

We gratefully acknowledge the technical assistance of Christine Bugay valdez and Mette Hougaard.

\section{Author details}

${ }^{1}$ Department of Clinical Biochemistry and Immunology, Statens Serum Institut, Copenhagen, Denmark. ${ }^{2}$ Department of Biomedical Sciences, University of Stellenbosch, Cape Town, South Africa. ${ }^{3}$ Department of Internal Medicine, Roskilde Hospital, Roskilde, Denmark. ${ }^{4}$ Department of Bacteriology, Statens Serum Institut, Copenhagen, Denmark. ${ }^{5}$ Department of Medicine B, Rigshospitalet, Copenhagen, Denmark.

\section{Authors' contributions}

PLH, PSA, JMS and MC Participated in the study design, PLH carried out the molecular genetic studies, PLH and FA participated in the sequence alignment and bioinformatics assessment of variants, PLH and MC drafted the manuscript, $\mathrm{OH}, \mathrm{MJ}$ and $\mathrm{HB}$ Performed clinical characterisation of the patients, MC: Conceived the study.

All authors read and approved the final manuscript.

\section{Competing interests}

The authors declare that they have no competing interests.

Received: 20 February 2011 Accepted: 3 October 2011 Published: 3 October 2011

\section{References}

1. Behr ER, McKenna WJ: Hypertrophic Cardiomyopathy. Curr Treat Options Cardiovasc Med 2002, 4(6):443-453.

2. Maron BJ: Hypertrophic cardiomyopathy: a systematic review. JAMA 2002, 287(10):1308-1320.

3. Andersen PS, Havndrup $O$, Hougs $L$, Sorensen $K M$, Jensen $M$, Larsen LA, Hedley P, Thomsen AR, Moolman-Smook J, Christiansen M, et al: Diagnostic yield, interpretation, and clinical utility of mutation screening of sarcomere encoding genes in Danish hypertrophic cardiomyopathy patients and relatives. Hum Mutat 2009, 30(3):363-370.

4. McNair WP, Ku L, Taylor MR, Fain PR, Dao D, Wolfel E, Mestroni L: SCN5A mutation associated with dilated cardiomyopathy, conduction disorder, and arrhythmia. Circulation 2004, 110(15):2163-2167.

5. Hesse M, Kondo CS, Clark RB, Su L, Allen FL, Geary-Joo CT, Kunnathu S, Severson DL, Nygren A, Giles WR, et al: Dilated cardiomyopathy is associated with reduced expression of the cardiac sodium channel Scn5a. Cardiovasc Res 2007, 75(3):498-509.

6. Bienengraeber M, Olson TM, Selivanov VA, Kathmann EC, O'Cochlain F, Gao F, Karger AB, Ballew JD, Hodgson DM, Zingman LV, et al: ABCC9 
mutations identified in human dilated cardiomyopathy disrupt catalytic KATP channel gating. Nat Genet 2004, 36(4):382-387.

7. Abbott GW, Goldstein SA: Potassium channel subunits encoded by the KCNE gene family: physiology and pathophysiology of the MinK-related peptides (MiRPs). Mol Interv 2001, 1(2):95-107.

8. Angelo K, Jespersen T, Grunnet M, Nielsen MS, Klaerke DA, Olesen SP: KCNE5 induces time- and voltage-dependent modulation of the KCNQ1 current. Biophys J 2002, 83(4):1997-2006.

9. Grunnet $\mathrm{M}$, Jespersen $\mathrm{T}$, Rasmussen $\mathrm{HB}$, Ljungstrom $\mathrm{T}$, Jorgensen $\mathrm{NK}$, Olesen SP, Klaerke DA: KCNE4 is an inhibitory subunit to the KCNQ1 channel. J Physiol 2002, 542(Pt 1):119-130.

10. Grunnet M, Rasmussen HB, Hay-Schmidt A, Rosenstierne M, Klaerke DA, Olesen SP, Jespersen T: KCNE4 is an inhibitory subunit to Kv1.1 and Kv1.3 potassium channels. Biophys J 2003, 85(3):1525-1537.

11. Lundby A, Olesen SP: KCNE3 is an inhibitory subunit of the Kv4.3 potassium channel. Biochem Biophys Res Commun 2006, 346(3):958-967.

12. Melman YF, Um SY, Krumerman A, Kagan A, McDonald TV: KCNE1 binds to the KCNQ1 pore to regulate potassium channel activity. Neuron 2004, 42(6):927-937

13. Xu X, Kanda VA, Choi E, Panaghie G, Roepke TK, Gaeta SA, Christini DJ, Lerner DJ, Abbott GW: MinK-dependent internalization of the IKs potassium channel. Cardiovasc Res 2009, 82(3):430-438.

14. Bianchi L, Shen Z, Dennis AT, Priori SG, Napolitano C, Ronchetti E, Bryskin R, Schwartz PJ, Brown AM: Cellular dysfunction of LQT5-minK mutants: abnormalities of IKs, IKr and trafficking in long QT syndrome. Hum Mol Genet 1999, 8(8):1499-1507.

15. Duggal $P$, Vesely MR, Wattanasirichaigoon D, Villafane J, Kaushik $V$, Beggs AH: Mutation of the gene for IsK associated with both Jervell and Lange-Nielsen and Romano-Ward forms of Long-QT syndrome. Circulation 1998, 97(2):142-146.

16. Hedley PL, Jorgensen P, Schlamowitz S, Moolman-Smook J, Kanters JK, Corfield VA, Christiansen M: The genetic basis of Brugada syndrome: a mutation update. Hum Mutat 2009, 30(9):1256-1266.

17. Hedley PL, Jorgensen $\mathrm{P}$, Schlamowitz S, Wangari R, Moolman-Smook J, Brink PA, Kanters JK, Corfield VA, Christiansen M: The genetic basis of long QT and short QT syndromes: a mutation update. Hum Mutat 2009, 30(11):1486-1511.

18. Paulussen $A D$, Gilissen RA, Armstrong $M$, Doevendans $P A$, Verhasselt $P$, Smeets HJ, Schulze-Bahr E, Haverkamp W, Breithardt G, Cohen N, et al: Genetic variations of KCNQ1, KCNH2, SCN5A, KCNE1, and KCNE2 in drug-induced long QT syndrome patients. J Mol Med 2004, 82(3):182-188.

19. Splawski I, Shen J, Timothy KW, Lehmann MH, Priori S, Robinson JL, Moss AJ, Schwartz PJ, Towbin JA, Vincent GM, et al: Spectrum of mutations in long-QT syndrome genes. KVLQT1, HERG, SCNSA, KCNE1, and KCNE2. Circulation 2000, 102(10):1178-1185.

20. Yang Y, Xia M, Jin Q, Bendahhou S, Shi J, Chen Y, Liang B, Lin J, Liu Y, Liu B, et al: Identification of a KCNE2 gain-of-function mutation in patients with familial atrial fibrillation. Am J Hum Genet 2004, 75(5):899-905.

21. Delpon E, Cordeiro JM, Nunez L, Thomsen PE, Guerchicoff A, Pollevick GD, Wu Y, Kanters JK, Larsen CT, Burashnikov E, et al: Functional Effects of KCNE3 Mutation and its Role in the Development of Brugada Syndrome. Circ Arrhythm Electrophysiol 2008, 1(3):209-218.

22. Ravn LS, Aizawa Y, Pollevick GD, Hofman-Bang J, Cordeiro JM, Dixen U, Jensen G, Wu Y, Burashnikov E, Haunso S, et al: Gain of function in IKs secondary to a mutation in KCNE5 associated with atrial fibrillation. Heart Rhythm 2008, 5(3):427-435.

23. Abbott GW, Butler MH, Bendahhou S, Dalakas MC, Ptacek $\sqcup$, Goldstein SA: MiRP2 forms potassium channels in skeletal muscle with Kv3.4 and is associated with periodic paralysis. Cell 2001, 104(2):217-231.

24. Roepke TK, Kontogeorgis A, Ovanez C, Xu X, Young JB, Purtell K, Goldstein PA, Christini DJ, Peters NS, Akar FG, et al: Targeted deletion of kcne2 impairs ventricular repolarization via disruption of I(K,slow1) and I (to,f). FASEB J 2008, 22(10):3648-3660.

25. Roepke TK, King EC, Reyna-Neyra A, Paroder M, Purtell K, Koba W, Fine E, Lerner DJ, Carrasco N, Abbott GW: Kcne2 deletion uncovers its crucial role in thyroid hormone biosynthesis. Nat Med 2009, 15(10):1186-1194.

26. Roepke TK, Purtell K, King EC, La Perle KM, Lerner DJ, Abbott GW: Targeted deletion of Kcne2 causes gastritis cystica profunda and gastric neoplasia. PLoS One 2010, 5(7):e11451.

27. Lundquist AL, Manderfield L, Vanoye CG, Rogers CS, Donahue BS, Chang PA, Drinkwater DC, Murray KT, George AL Jr: Expression of multiple
KCNE genes in human heart may enable variable modulation of I(KS). Mol Cell Cardiol 2005, 38(2):277-287.

28. Abbott GW, Goldstein SA: Disease-associated mutations in KCNE potassium channel subunits (MiRPs) reveal promiscuous disruption of multiple currents and conservation of mechanism. FASEB J 2002, 16(3):390-400

29. Furukawa T, Ono Y, Tsuchiya H, Katayama Y, Bang ML, Labeit D, Labeit S, Inagaki N, Gregorio CC: Specific interaction of the potassium channel beta-subunit minK with the sarcomeric protein T-cap suggests a Ttubule-myofibril linking system. J Mol Biol 2001, 313(4):775-784.

30. Bos JM, Poley RN, Ny M, Tester DJ, Xu X, Vatta M, Towbin JA, Gersh BJ, Ommen SR, Ackerman MJ: Genotype-phenotype relationships involving hypertrophic cardiomyopathy-associated mutations in titin, muscle LIM protein, and telethonin. Mol Genet Metab 2006, 88(1):78-85.

31. Knoll R, Hoshijima M, Hoffman HM, Person V, Lorenzen-Schmidt I, Bang ML, Hayashi T, Shiga N, Yasukawa H, Schaper W, et al: The cardiac mechanical stretch sensor machinery involves a $Z$ disc complex that is defective in a subset of human dilated cardiomyopathy. Cell 2002, 111(7):943-955.

32. Radicke S, Cotella D, Graf EM, Banse U, Jost N, Varro A, Tseng GN, Ravens U, Wettwer E: Functional modulation of the transient outward current Ito by KCNE beta-subunits and regional distribution in human non-failing and failing hearts. Cardiovasc Res 2006, 71(4):695-703.

33. Jurkat-Rott K, Lehmann-Horn F: Periodic paralysis mutation MiRP2-R83H in controls: Interpretations and general recommendation. Neurology 2004, 62(6):1012-1015

34. McKenna WJ, England D, Doi YL, Deanfield JE, Oakley C, Goodwin JF: Arrhythmia in hypertrophic cardiomyopathy. I: Influence on prognosis $\mathrm{Br}$ Heart J 1981, 46(2):168-172.

35. Van Laer L, Carlsson Pl, Ottschytsch N, Bondeson ML, Konings A, Vandevelde A, Dieltjens N, Fransen E, Snyders D, Borg E, et al: The contribution of genes involved in potassium-recycling in the inner ear to noise-induced hearing loss. Hum Mutat 2006, 27(8):786-795.

36. Westenskow P, Splawski I, Timothy KW, Keating MT, Sanguinetti MC: Compound mutations: a common cause of severe long-QT syndrome. Circulation 2004, 109(15):1834-1841.

37. Richardson P, McKenna W, Bristow M, Maisch B, Mautner B, O'Connell J Olsen E, Thiene G, Goodwin J, Gyarfas I, et al: Report of the 1995 World Health Organization/International Society and Federation of Cardiology Task Force on the Definition and Classification of cardiomyopathies. Circulation 1996, 93(5):841-842.

38. ten Cate FJ, Hugenholtz PG, van Dorp WG, Roelandt J: Prevalence of dignostic abnormalities in patients with genetically transmitted asymmetric septal hypertrophy. Am J Cardiol 1979, 43(4):731-737.

39. Wildeman M, van Ophuizen E, den Dunnen JT, Taschner PE: Improving sequence variant descriptions in mutation databases and literature using the Mutalyzer sequence variation nomenclature checker. Hum Mutat 2008, 29(1):6-13.

40. Ehrlich JR, Zicha S, Coutu P, Hebert TE, Nattel S: Atrial fibrillationassociated minK38G/S polymorphism modulates delayed rectifier current and membrane localization. Cardiovasc Res 2005, 67(3):520-528.

41. Dias Da Silva MR, Cerutti JM, Arnaldi LA, Maciel RM: A mutation in the KCNE3 potassium channel gene is associated with susceptibility to thyrotoxic hypokalemic periodic paralysis. J Clin Endocrinol Metab 2002, 87(11):4881-4884.

42. Hofman-Bang J, Jespersen T, Grunnet M, Larsen LA, Andersen PS, Kanters JK, Kjeldsen K, Christiansen M: Does KCNE5 play a role in long QT syndrome? Clin Chim Acta 2004, 345(1-2):49-53.

doi:10.1186/1477-5751-10-12

Cite this article as: Hedley et al:: The KCNE genes in hypertrophic cardiomyopathy: a candidate gene study. Journal of Negative Results in BioMedicine 2011 10:12. 